\title{
Growth Sustaining Aspects of Excoecaria Agallocha L. for Strategic Afforestation Protocols
}

\author{
Neethu G. Pillai $^{{ }^{*}}$, Harilal C.C. ${ }^{2}$ \\ ${ }^{1,2}$ Division of Environmental Science, Dep. of Botany, University of Calicut, Malappuram District, Kerala - 673 635, India \\ * Corresponding author: neethupillai9@gmail.com
}

Available online at: www.isroset.org

Accepted: 18/Aug/2018, Online: 30/Aug/ 2018

\begin{abstract}
Restoration/ afforestation initiatives on mangroves primarily require reliable information on the growth requirements of the targeted mangrove species. The present investigation was carried out to evaluate the hydrogeochemical, sedimentological and climatological conditions ideal for the growth and establishment of the mangrove species Excoecaria agallocha L. in pursuit of their afforestation practices. Assessment of the physicochemical characteristics of water and soil / sediment along with climatological attributes from three heterogeneous habitats falling in the coastal environments of Kerala was monitored monthly for a period of one year for deriving conclusions regarding the growth requirements of E. agallocha. Statistical analysis revealed the most vital attributes of water which influence the growth of E. agallocha are water pH, turbidity, total suspended solids, resistivity, acidity, alkalinity, phosphorous and potassium and also the sedimentological characteristics such as $\mathrm{pH}$, moisture \%, sand, silt, clay \%, organic carbon, nitrogen, potassium and sodium. The study as a whole reported the capability of E. agallocha to cope up with different hydrological and sedimentological conditions in terms of tolerance or augmented range, which will form a basis for future afforestation initiatives.
\end{abstract}

Keywords- Excoecaria agallocha, growth sustaining conditions, water quality, sediment quality, climatology

\section{Introduction}

Any afforestation or restoration endeavor on mangroves primarily requires reliable information on ecology, hydrology and sedimentology that control the successful growth of the targeted mangrove species. Among all such vital attributes, water and sediment quality are known to have supreme influence on the growth of mangroves [1]. In light of this, the present investigation was carried out with the objective of evaluating the hydrogeochemical, sedimentological and climatological conditions ideal for the growth and establishment of the mangrove species E. agallocha in pursuit of their utilization for species specific afforestation practices.

\section{Materials and Methods}

Excoecaria agallocha L. is a small to medium sized back mangrove species and often exploits open areas along with some marine and coastal protected regions. Three heterogeneous natural habitats confining to the coastal environments of Kerala (Fig. 1) have been fixed for assessing the growth sustaining conditions of the mangrove species E. agallocha (Table 1). Location 1 (Ayiramthengu) was falling in Kollam district. Location 2 (Kumbalam) of Ernakulam District was $102 \mathrm{~km}$ far from Location 1 and Location 3 (Thekkumbad) was in Kannur district, which was 294 km from location 2.

Table 1. Study Area

\begin{tabular}{|c|c|c|c|c|}
\hline $\begin{array}{c}\text { Sl. } \\
\text { No: }\end{array}$ & Location & District & Latitude & Longitude \\
\hline 1 & Ayiramthengu & Kollam & $9^{\circ} 07^{\prime} 28.71^{\prime \prime} \mathrm{N}$ & $76^{\circ} 28^{\prime} 38.89^{\prime \prime} \mathrm{E}$ \\
\hline 2 & Kumbalam & Ernakulam & $9^{\circ} 54^{\prime} 15.02^{\prime \prime} \mathrm{N}$ & $76^{\circ} 18^{\prime} 45.49^{\prime \prime} \mathrm{E}$ \\
\hline 3 & Thekkumbad & Kannur & $11^{\circ} 58^{\prime} 00.71^{\prime \prime} \mathrm{N}$ & $75^{\circ} 17^{\prime} 49.79^{\prime \prime} \mathrm{E}$ \\
\hline
\end{tabular}




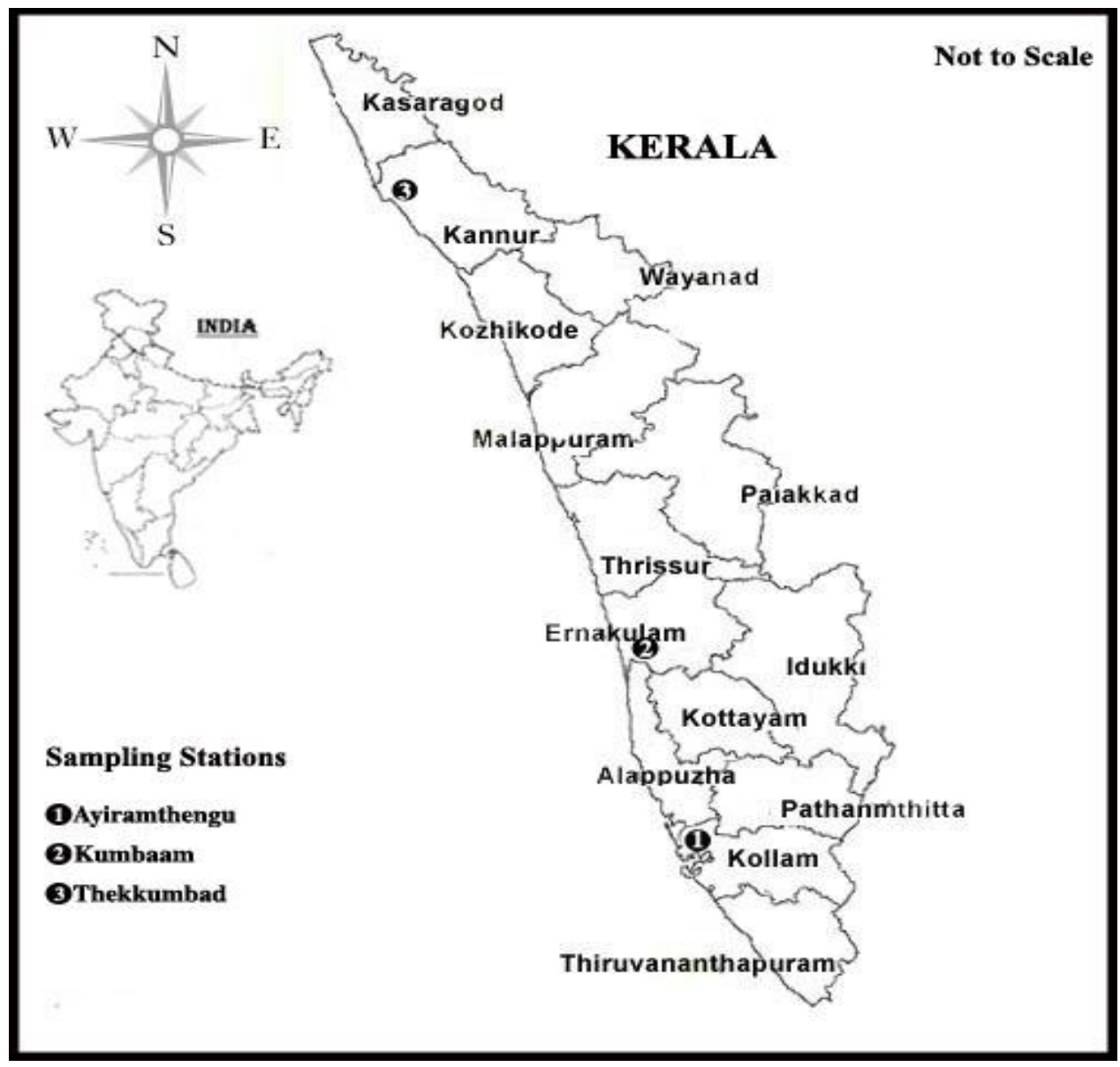

Fig. 1. Study Area

The study was carried out during 2013 to 2014. Monthly visits to these habitats were carried out and both water and sediment samples were collected. Estimation of the physicochemical characteristics of water and soil / sediments were worked out for deriving conclusions regarding their growth sustaining conditions along with the range of conditions to which they are adjusted to. Water quality parameters analyzed include pH (Systronics, MK IV), turbidity (Systronics, Model 341), TS, TDS, TSS (Gravimetric method), salinity, resistivity, conductivity (Eutech PCD, 650), acidity, alkalinity, total hardness, calcium, magnesium, chloride (Titrimetric method), sulphate (Turbidimetric method), sodium and potassium (Flame photometric method), total nitrogen (Kjeldahl Method) and phosphorous (Stannous chloride method) [2, 3]. Similarly worked out the pH, moisture percentage, organic carbon, total nitrogen, total phosphorous, sodium and potassium content of sediment samples [3, $4,5]$. Also the textural percentages of sand, silt and clay associated with soil/sediment samples were worked out following International Pipette Method. The data concerning meteorological characteristics of the study area were obtained from India meteorological department. The results were then analyzed.

\section{Results}

Many ecological factors strongly influence the growth and development of mangroves [6]; among them, water and sediment quality are known to have supreme influence [1]. The mean values of water, sediment and climatological parameters together with their standard deviation from habitats containing E. agallocha are estimated.

The estimated percentages of sand, silt and clay were used to determine the textural class of the soil. This was achieved through the triangular textural diagram, proposed by the United States Department of Agriculture (USDA) [7]. Based on the physical composition, the textural classes of sediments noticed along the habitats of E. agallocha were Sand, Sandy Loam and Loamy Sand (Fig. 2). 


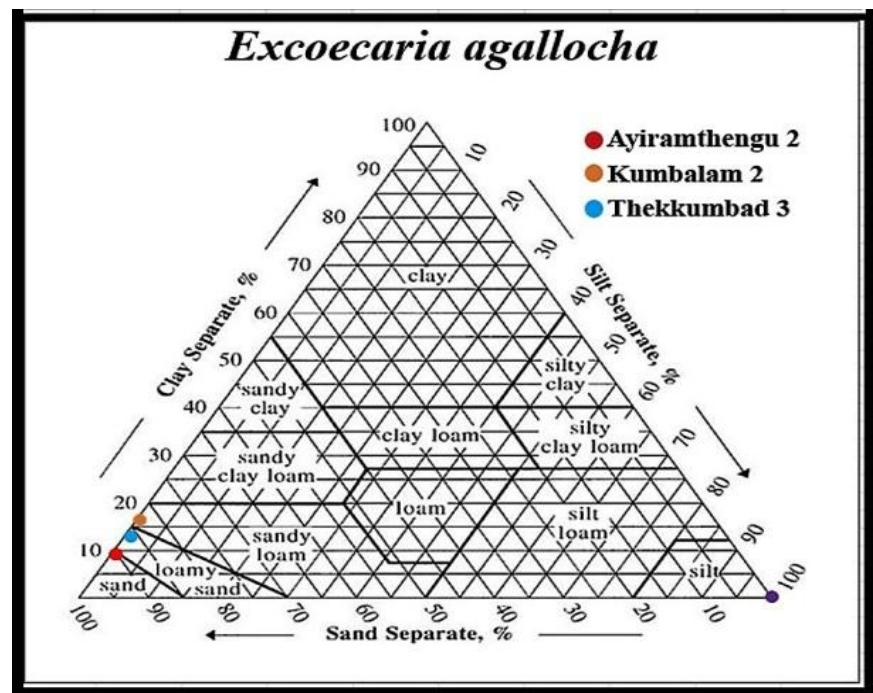

Fig. 2. Sediment class preference of the mangrove species E. agallocha

Data pertaining to climatological attributes like atmospheric maximum - minimum temperature $\left({ }^{\circ} \mathrm{C}\right)$, Total Rainfall $(\mathrm{MMS})$ and Relative Humidity (\%) with respect to all the locations under study has been collected and reported.

Upon compiling all the results, it can be stated that, even though the mangroves are growing in a wider range of environmental conditions, each species has its own range of tolerance to different hydrogeochemical, sedimentological and climatological attributes along their natural habitats. In the present investigation, the range of environmental attributes influencing the growth of selected mangrove species has been categorized into tolerance range and augmented range. Tolerance range is the ideal range, at which a particular species can flourish well along their natural environmental settings and the augmented range is the range that is acquired by adapting to an uncertain environmental condition. The ranges of various environmental attributes influencing the growth of E. agallocha are depicted in Table 2.

Table 2. Range of environmental attributes influencing the growth of E. agallocha.

\begin{tabular}{|c|c|c|c|}
\hline Sl.No. & Parameters & Tolerance range & Augmented range \\
\hline \multicolumn{4}{|c|}{ Hydrological attributes } \\
\hline 1. & $\mathbf{p H}$ & $6.75-7.39$ & $5.06-8.31$ \\
\hline 2. & Turbidity (NTU) & $5.677-9.54$ & $1.5-26.9$ \\
\hline 3. & TS (mg/l) & $10,433.3-23,500.0$ & $200-45800$ \\
\hline 4. & TDS (ppt) & $9.86-22.7$ & $0.2-45.6$ \\
\hline 5. & TSS (mg/l) & $566.67-1600.0$ & $0-6000$ \\
\hline 6. & Acidity (mg/l) & 27.13-39.356 & $11-63.8$ \\
\hline 7. & Alkalinity (mg/l) & 122.08-172.08 & $60-215$ \\
\hline 8. & Hardness (mg/l) & 1736.91-3279.67 & $22-7660$ \\
\hline 9. & Calcium (mg/l) & 130.83-273.32 & $6.41-680.85$ \\
\hline 10. & Magnesium (mg/l) & 343.34-598.78 & $0.97-1524.09$ \\
\hline 11. & Chloride (mg/l) & $7669.78-13166.84$ & $227.2-26,128$ \\
\hline 12. & Sulphate (mg/l) & $35.27-52.41$ & $0.5-128$ \\
\hline 13. & Sodium (ppt) & $8.44-14.30$ & $0.075-29.8$ \\
\hline 14. & Nitrogen (mg/l) & $63.33-69.75$ & $22-220$ \\
\hline 15. & Phosphorous (mg/l) & 18.2-42.6 & $0.2-110$ \\
\hline 16. & Potassium (mg/l) & 120.0-387.08 & $0-1700$ \\
\hline 17. & Salinity (ppt) & 8.52-19.067 & $0.045-37.21$ \\
\hline 18. & Resistivity ( $\Omega$ ) & 66.07-2317.91 & $18.06-12,270$ \\
\hline 19. & Conductivity & 13.65-29.025 & $0.0795-54.24$ \\
\hline \multicolumn{4}{|c|}{ Sedimentological attributes } \\
\hline 20 & $\mathbf{p H}$ & $6.63-7.247$ & $4.1-8.16$ \\
\hline
\end{tabular}




\begin{tabular}{|c|c|c|c|}
\hline 21 & Moisture \% & 8.88-11.518 & $4.25-16.2$ \\
\hline 22 & Organic carbon (g/kg) & $17.5-35.1$ & $0.4-110.5$ \\
\hline 23 & Total nitrogen (mg/kg) & 788.06-1628.7 & $630.45-3572.55$ \\
\hline 24 & Total phosphorous (mg/kg) & $15.4-43.1$ & $8.2-69.6$ \\
\hline 25 & Potassium (mg/kg) & $35.158-56.792$ & $0.2-138$ \\
\hline 26 & Sodium (ppt) & 0.316-0.44 & $0.0441-1.355$ \\
\hline 27 & Sand \% & 83.3-90.358 & $61.7-97.9$ \\
\hline 28 & Silt \% & 0.38-0.983 & $0.1-6.7$ \\
\hline 29 & Clay \% & $9.067-16.317$ & $0.7-38.2$ \\
\hline \multicolumn{4}{|c|}{ Climatological attributes } \\
\hline 30. & Atm.Max.Temp $\left({ }^{\circ} \mathrm{C}\right)$ & 32.33-32.95 & $28-36.6$ \\
\hline 31. & Atm.Min.Temp $\left({ }^{\circ} \mathrm{C}\right)$ & 22.133-24.358 & $20.4-26.9$ \\
\hline 32. & Total rainfall (MMS) & $223.29-249.533$ & $0-1131.6$ \\
\hline 33. & R.H \% at $0830 \mathrm{hrs}$ & 80.75-86.083 & $65-97$ \\
\hline 34. & R.H \% at 1730 hrs & $71.833-74.833$ & $53-94$ \\
\hline
\end{tabular}

Physico chemical attributes of both water and sediment along selected habitats were further analyzed statistically to find out the discrepancy among different sites and seasons. Seasonal and site specific mean values of each parameters were subjected to two way ANOVA and found out the variations among the locations as well as the seasons. Such variations in each parameter with respect to sites and seasons were considered towards elucidating each of their influence on the growth of mangrove species. Accordingly, the most vital physico chemical attributes of water and sediment that are likely to influence the growth of each mangrove species can be enumerated. Since a uniform pattern of climatological conditions has been experienced along all the locations under study, statistical analysis for elucidating each of their influence on mangrove growth was not attempted.

The study as a whole revealed that, the heterogeneous habitats of the mangrove species E. agallocha showed stability in their water quality attributes such as $\mathrm{pH}$, turbidity, total suspended solids, resistivity, acidity, alkalinity, phosphorous and potassium and also with respect to sedimentological characteristics such as $\mathrm{pH}$, moisture \%, sand, silt, clay \%, organic carbon, nitrogen, potassium and sodium (Fig.3).
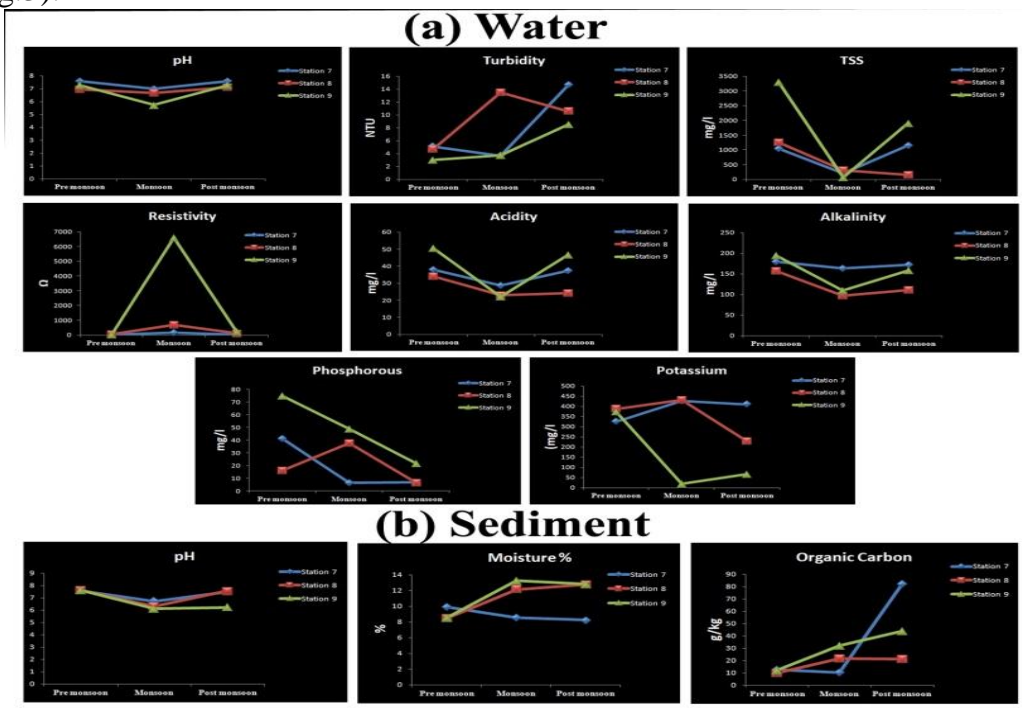

(b) Sediment
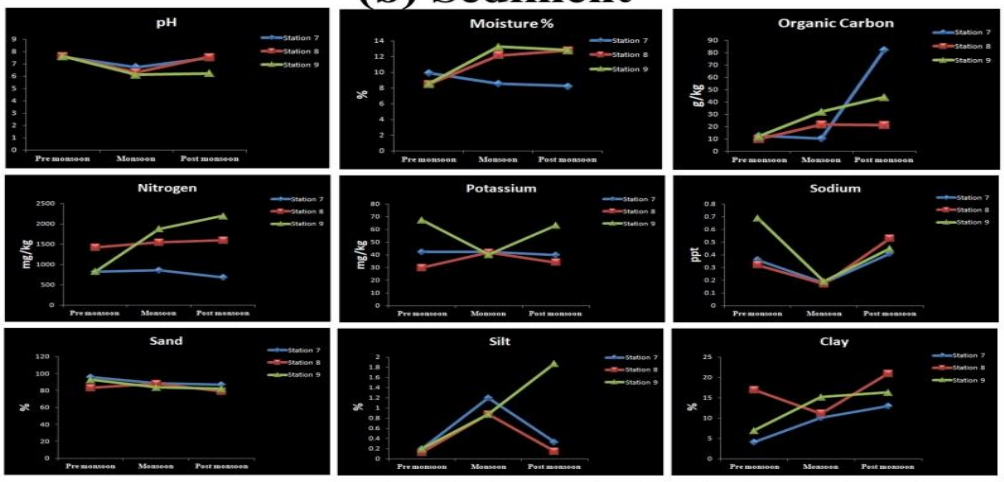

Fig. 3. Physico chemical attributes influencing the growth of E. agallocha 
The physico-chemical attributes of both water and sediment that showed no significant variations between sites and seasons can be confirmed as the growth promoting factors for the mangrove species under study. Thus, the study as a whole reports the capability of the mangrove species to cope up with different hydrogeochemical and sedimentological conditions in terms of tolerance range or augmented range.

\section{Discussion}

The present study evaluated the hydrogeochemical, sedimentological and climatological conditions ideal for the growth and establishment of the mangrove species E. agallocha in pursuit of their utilization for species specific afforestation practices. The most vital physico chemical attributes of water and sediment that are likely to influence the growth of the mangrove species can be enumerated using variation analysis. Comparison of the results with earlier reports was carried out to derive strategic conclusions.

The present study reported the tolerance and augmented range of $\mathrm{pH}$ of water as 6.758 to 7.39 and 5.06 to 8.31 respectively. Paramasivam and Kannan, 2005, in their studies on the Muthupettai mangrove ecosystem, showed the range of hydrological $\mathrm{pH}$ in mangrove area as 7.1-8.7 and in 2012, Manju et al., studied the entire mangrove ecosystems of Kerala and reported the $\mathrm{pH}$ of water as $7.1-8.05[8,9]$. Tolerance range of 5.678 to $9.542 \mathrm{NTU}$ and augmented range of 1.5 to 26.9 NTU for turbidity is noted for Excoecaria agallocha. A value of almost similar range (10.43 NTU) has been reported by Shilna et al. (2016) [10]. E. agallocha is with a range of tolerance 566.67 to $1600 \mathrm{mg} / \mathrm{l}$ respectively towards TSS. The range of tolerance of acidity and alkalinity are 27.133 to $39.356 \mathrm{mg} / \mathrm{l}$ and 122.083 to $172.083 \mathrm{mg} / \mathrm{l}$ respectively. In 2016 , Shilna et al., reported the annual range of acidity and alkalinity of the mangrove area with all the selected mangrove species as $8.24 \mathrm{mg} / \mathrm{l}$ and $100.79 \mathrm{mg} / \mathrm{l} \mathrm{respectively}$ and in 2012, Manju et al., reported the annual alkalinity of $77.91 \mathrm{mg} / \mathrm{l}$ from the mangrove ecosystems of Kerala [9, 10]. E. agallocha have range of tolerance towards $\mathrm{P}$ and $\mathrm{K}$ is 18.2 to $42.6 \mathrm{mg} / \mathrm{l}$ and 120.0 to $387.08 \mathrm{mg} / \mathrm{l}$ respectively. Phosphorous and Potassium are the major nutrients in the mangrove sediments studied and reported from various natural mangrove habitats of Kerala and the annual average values reported were $9.61 \mu \mathrm{M}$ and $105.38 \mathrm{mg} / \mathrm{l}$ respectively (Manju et al., 2012) [9].

With respect to sediments, the study reported a range of tolerance and augmented values towards pH, moisture percentage and organic carbon as 6.638 to $7.247,8.888$ to $11.518 \%$ and 1.75 to $3.511 \mathrm{~g} / \mathrm{kg}$ respectively. Saravanakumar et al. (2008) reported the range of organic carbon from the mangrove ecosystem of Kachchh - Gujarat as 2.9 to 25.6 g/kg [11]. The distribution of total organic carbon closely followed the distribution of sediment type i.e., as sediment is low in clay content, the total organic carbon content is also low and as the clay content increased, the total organic carbon content also increased (Reddy and Hariharan, 1986) [12]. Various studies have also reported that, soil organic carbon and $\mathrm{pH}$ are the major factors having most significant influence on the growth and establishment of mangroves (Clough, 1984 and Yang et al., 2013) [13, 14].

As far as the present study concerned, the tolerance and augmented range of the species to sediment NPK is (788.063 to $1628.7,15.4$ to 43.1 and 35.158 to $56.792 \mathrm{mg} / \mathrm{kg})$ and $(630.45$ to $3572.55,8.2$ to 69.6 and 0.2 to 138$) \mathrm{mg} / \mathrm{kg}$ respectively. A recent study carried out in the mangrove ecosystem of Ayiramthengu, Kerala possessing these mangrove species reported a range of $\mathrm{P}$ and $\mathrm{K}$ as 29.5 to $57.9 \mathrm{Kg} / \mathrm{ha}$ and 231 to $440 \mathrm{Kg} / \mathrm{ha}$ respectively. The tolerance range of the species towards sodium is 0.316 to $0.441 \mathrm{ppt}$ and that of sand, silt and clay percentages are 83.3 to $90.358,0.383$ to 0.983 and 9.067 to $16.317 \%$ respectively. More or less similar results have been reported by Saravanakumar et al. (2008) [11]. The study reported ranges of sediment textures in terms of \% of sand, clay and silt as 0.26-19.2, 7.6-47 and 47-87.4\% respectively. Studies using textural triangles revealed that the nature of soil / sediment in all the locations studied were silty loam, silty clay and silty clay loam.

In general, mangroves are inimitable intertidal ecosystems with unique features, having own adaptations to cope up with extreme environmental conditions. A prior assessment of the area with respect to the tolerance / augmented range of various growth sustaining conditions of the mangrove species (E. agallocha) will help in the futuristic assessment of the feasibility of the area with regard to the introduction of E. agallocha.

\section{Conclusion}

The present study has been carried out to evaluate the environmental factors (water, soil / sediment and climate) determining the growth of the mangrove species E. agallocha along heterogeneous habitats of Kerala.

The results as a whole revealed that between different sites and seasons, no significant variations have been noticed in water quality attributes like $\mathrm{pH}$, turbidity, total suspended solids, resistivity, acidity, alkalinity, phosphorous and potassium and also the sedimentological characteristics such as $\mathrm{pH}$, moisture \%, sand, silt, clay \%, organic carbon, nitrogen, potassium and sodium 
content of sites having E. agallocha. The study as a whole reports the capability of the mangrove species E. agallocha to cope up with different hydrological and sedimentological conditions in terms their tolerance range or augmented range. Results of the textural characterization of sediments revealed Sand, Sandy Loam and Loamy Sand as ideal environments for the growth of E. agallocha.

Thus the study proposed that the 'tolerance range' of a species with respect to the site is a mandatory requirement towards including them in afforestation purposes, whereas 'augmented range' is not a natural one as it is acquired by the species after acclimatization in the new area. In conclusion, the study emphasized that all the afforestation/ restoration practices of mangroves must be either species or site specific.

\section{References}

[1]. Thom, B. G., Mangrove ecology and deltaic geomorphology: Tabasco, Mexico. The Journal of Ecology, 55: 301-343, 1967.

[2]. APHA, Standard Methods for the Examination of Water and Wastewater. 21st Edition, American Public Health Association/American Water Works Association/Water Environment Federation, Washington DC., 2005.

[3]. Trivedi, R.K., Goel, P.K., Trisal, C.L. Practical methods in Ecology and Environmental sciences. Environ. Public. Karad, (India), 1987.

[4]. Subramanyam N.S., Sambamuthy A.V.S.S., Ecology, Narosa Publishing House, Delhi. 616, 2002.

[5]. Jackson, M.L., Soil Chemical Analysis. Prentice Hall of India Pvt. Ltd., New Delhi, 498, 1973.

[6]. Kjerfve, B., Lacerda, L.D., Rezende, C.E., Ovalle, A.R.C., Hydrological and hydrogeochemical variations in mangrove ecosystems. In : Mangrove ecosystems in tropical America: structure, function and management. Yanez-Arancibia, A. and Lara-Dominquez, A.L. (eds.) Mexico), pp. 71-81, 1999.

[7]. USDA Soil Survey Division Staff., "Soil survey manual." Soil Conservation Service. U.S. Department of Agriculture Handbook $18,1993$.

[8]. Paramasivam, S., Kannan, L., Physico-chemical characteristics of Muthupettai mangrove environment, Southeast coast of India. International Journal of Ecology and Environmental Sciences, 31: 273-278, 2005.

[9]. Manju, M.N., Resmi, P., Girish Kumar, T.T., Raathesh Kumar, C.S., Rahul, R., Joseph, M.M., Chandramohankumar, N., Assessment of water quality parameters in mangrove ecosystems along Kerala coast: a statistical approach. Int. J. Environ. Res., 6: 893-902, 2012.

[10]. Shilna E.P., Sajith U., Harilal C.C. Surveillance on Water Quality in Pursuit of Mangrove Afforestation along the Coastal and Inland Aquatic Environments of Malappuram District, Kerala, India. International Research Journal of Environmental sciences, 5: 41-50, 2016.

[11]. Saravanakumar, A., Rajkumar, M., Serebiah, J. S., Thivakaran, G. A. Seasonal variations in physico-chemical characteristics of water, sediment and soil texture in arid zone mangroves of Kachchh-Gujarat. Journal of environmental Biology: 29, 725-732, 2008.

[12]. Reddy, Venkataswamy, H.R., Hariharan V. Distribution of nutrients in the sediments of the Netravathi-Gurupur estuary, Mangalore. Ind. J. Fish., 33: 123-126, 1986.

[13]. Clough, B. F. Growth and salt balance of the mangroves Avicennia marina (Forsk.) Vierh. and Rhizophora stylosa Griff. in relation to salinity, Functional Plant Biology, 11: 419-430, 1984.

[14]. Yang, J., Gao, J., Cheung, A., Liu, B., Schwendenmann, L., Costello, M. J., Vegetation and sediment characteristics in an expanding mangrove forest in New Zealand. Estuarine, Coastal and Shelf Science: 134, 11-18, 2013. 